\title{
Intra-tumoral molecular heterogeneity in benign and malignant pheochromocytomas and extra-adrenal sympathetic paragangliomas
}

\author{
Esther Korpershoek*, Claudia K Stobbe*, Francien H van Nederveen, \\ Ronald $R$ de Krijger and Winand N M Dinjens
}

\author{
Department of Pathology, Josephine Nefkens Institute, Erasmus MC, University Medical Center, Room Ae304, PO Box 2040, \\ 3000 CA Rotterdam, The Netherlands \\ (Correspondence should be addressed to E Korpershoek; Email: e.korpershoek.1@erasmusmc.nl) \\ *(E Korpershoek and C K Stobbe contributed equally to this work)
}

\begin{abstract}
Pheochromocytomas (PCCs) and extra-adrenal sympathetic paragangliomas (sPGLs) are catecholamine-producing tumors occurring in the context of hereditary tumor syndromes, with known germline mutations, and as sporadic tumors. The pathogenesis of sporadic PCC and SPGL is poorly understood, and little is known about intra-tumoral heterogeneity with respect to molecular aberrations. Since knowledge on intra-tumoral heterogeneity is important for understanding the pathogenesis of these tumors, we investigated 12 benign and 8 malignant PCCs and sPGLs for loss of heterozygosity $(\mathrm{LOH})$ on DNA extracted from different regions of each tumor and from metastases. LOH markers were selected on chromosomal regions frequently deleted in PCC, including 1p, 3q, 3p, and 11p. Benign tumors were found to have less intratumoral heterogeneity (overall $8 \%$ ) than malignant tumors (overall $23 \%$ ), with the highest frequencies for chromosome 1p36 in the benign tumors (17\%) and 1p13 and 3q24 in malignant tumors (both $38 \%$ ). In addition, differences in $\mathrm{LOH}$ patterns were detected between paired primary malignant tumors, and their metastases and different LOH patterns were observed in bilateral PCC of a multiple endocrine neoplasia type 2 patient. We demonstrate that malignant PCC and sPGL have more intra-tumoral molecular heterogeneity than benign tumors, which suggests that benign and malignant PCC and SPGL have a different pathogenesis.
\end{abstract}

Endocrine-Related Cancer (2010) 17 653-662

\section{Introduction}

Pheochromocytomas (PCCs) are rare catecholamineproducing neuroendocrine tumors arising from chromaffin cells of the adrenal medulla. Extra-adrenal sympathetic paragangliomas (sPGLs) were previously known as extra-adrenal PCC. sPGLs are neuroendocrine tumors, mostly found in the abdomen, and usually produce catecholamines. PCC and sPGL are histologically indistinguishable, and share many clinical features, although sPGLs are more frequently malignant than PCC (Gimenez-Roqueplo et al. 2003, Lenders et al. 2005, Benn et al. 2006, Amar et al. 2007, Pacak et al. 2007).
Most PCCs are sporadic but up to $24 \%$ are associated with hereditary syndromes such as multiple endocrine neoplasia type 2 (MEN 2 caused by germline mutations in the proto-oncogene RET), Von HippelLindau disease (VHL caused by germline mutations in the tumor suppressor gene $V H L$ ), PCC-PGL syndrome (caused by germline mutations in one of the tumor suppressor genes $S D H B, S D H C, S D H D$, or $S D H A F 2$ ), and neurofibromatosis type 1 (NF1 caused by germline mutations in the NF1 tumor suppressor gene; Lenders 2005 \#37, Bayley 2010 \#208). The percentage of PCC associated with familial syndromes is higher than previously assumed, as several studies have demonstrated 
germline mutations in PCC susceptibility genes in apparently sporadic PCC (Neumann et al. 2002, Korpershoek et al. 2006, Cascon et al. 2009).

While loss of chromosome $1 \mathrm{p}$ is the most common genetic aberration reported in sporadic PCC (Dannenberg et al. 2000, Edstrom et al. 2000, Cascon et al. 2005, van Nederveen et al. 2009), particular genetic alterations have been demonstrated in syndrome-related PCC (Edstrom et al. 2000, Lui et al. 2002, Jarbo et al. 2005). Generally, MEN 2-related PCCs show loss of chromosomes 1p and 3q (Edstrom et al. 2000, Jarbo et al. 2005), SDHD-related PCCs and PGLs display loss of chromosome 11 (Hensen et al. 2004), and in NF1-related tumors, frequent loss of $1 \mathrm{p}$ and $17 \mathrm{q}$ is found (Edstrom et al. 2000, Bausch et al. 2007).

Few studies have demonstrated that sporadic PCCs have similar genetic aberrations as those found in syndrome-related tumors, such as loss of chromosomes 1p, 3p, 3q, 11p, and 11q (Dannenberg et al. 2000, Edstrom et al. 2000, Cascon et al. 2005, van Nederveen et al. 2009). Although the results at large of these studies are in agreement with each other, there are also differences. In a previous study, we have shown loss of chromosome 6 in 34\% of sporadic PCC (Dannenberg et al. 2000), while this relatively high percentage was not found in other studies (Edstrom et al. 2000, Cascon et al. 2005). In addition, Cascon et al. (2005) reported loss of chromosome $8 p$ in $62 \%$ of PCC, whereas this high percentage was not observed in other studies (Dannenberg et al. 2000, Edstrom et al. 2000, van Nederveen et al. 2009). These discrepancies could be due to geographical variations and hereditary background of the patients, differences in methods, but can also be the effect of intra-tumoral molecular heterogeneity.

Intra-tumoral molecular heterogeneity has been demonstrated in many different tumors, such as in renal tumors (Nenning et al. 1997), head and neck squamous cell carcinomas (Califano et al. 1996), lung tumors (Blackhall et al. 2004), cervical cancer (Bachtiary et al. 2006), and meningiomas (Sayagues et al. 2004), but has been poorly investigated in PCC. Jarbo et al. (2005) reported that the ratios of chromosome 22q loss in some PCC samples were higher than expected for a single allele ratio, and suggested this could be due to intra-tumoral heterogeneity. Diaz-Cano et al. (2000) investigated heterogeneity of sporadic and MEN 2-related PCC and adrenal medullary hyperplasia (AMH) nodules, by determining the methylation patterns of the androgen receptor $(A R)$ gene, localized on the $\mathrm{X}$-chromosome. All informative AMH showed concordant inactivation of the same alleles in different nodules from the same adrenal gland, suggesting that these AMH nodules arose from a common progenitor and are clonally related proliferations. In addition, the authors reported that a high percentage of sporadic PCC, benign as well as malignant, also show intra-tumoral concordant inactivation of the same $A R$ alleles, and therefore, PCCs were considered monoclonal in origin. Apart from this study, no reports exist about intra-tumoral heterogeneity of PCC on the molecular level.

PCC and SPGL are, as most other tumors, considered as monoclonal proliferations originating from one transformed cell. Transformation of a normal cell into a tumor cell is caused by the accumulation of mutations, among others in oncogenes and tumor suppressor genes. This implies that mutations occurring early in tumorigenesis are present in each individual tumor cell, whereas DNA aberrations that occurred later, during tumor growth, can be present only in a subpopulation of tumor cells. When investigating multiple, macroscopically separated, intra-tumoral regions for DNA aberrations, homogeneity of mutations indicates early aberrations, whereas heterogeneity points to later occurrence.

Molecular heterogeneity is important for elucidating the molecular pathogenesis of PCC. In addition, intra-tumoral heterogeneity is important for the interpretation of loss of heterozygosity $(\mathrm{LOH})$ and comparative genomic hybridization $(\mathrm{CGH})$ results in general. Furthermore, heterogeneity of PCC has never been thoroughly investigated. Therefore, we systematically investigated $\mathrm{LOH}$ in four macroscopically separated parts within each of 12 benign tumors (11 PCCs and 1 sPGL) from 11 patients, and 8 malignant tumors (seven PCCs and one sPGL) and 8 metastases from eight patients.

\section{Materials and methods}

\section{Patients}

Nineteen patients with PCC or sPGL were selected, of whom 11 had benign tumors (ten PCCs and one sPGL) and 8 had malignant tumors (seven PCCs and one sPGL). All eight patients with malignant tumors had distant metastases verified by histology. The tumors were retrieved from the archives of the Departments of Pathology of the Erasmus MC, University Medical Center, Rotterdam (15 cases), Maasstad Hospital, Rotterdam (1 case), University Medical Center Utrecht (1 case), Albert Schweitzer Hospital Dordrecht (1 case), and PAMM foundation, Veldhoven (1 case), 
The Netherlands. The tumors were anonymously used according to the code for adequate secondary use of tissue, code of conduct: 'Proper Secondary Use of Human Tissue' established by the Dutch Federation of Medical Scientific Societies (http://www.federa.org).

The benign series included six sporadic cases and five patients with syndrome-related tumors: two patients with NF1 (clinically determined) and one patient with MEN 2 (RET germline mutation Cys634Arg) of whom both tumors (left and right adrenal) were investigated and two patients with the PCC-PGL syndrome (SDHD germline mutation Asp92Tyr). One sporadic patient with a benign PCC was also diagnosed with a clear cell renal cell carcinoma (RCC). Although an RCC can be a feature of VHL disease, genetic analysis did not reveal a germline $V H L$ mutation. The malignant series was comprised of seven sporadic PCCs, one PCC-PGL syndrome-related sPGL ( $S D H D$ germline mutation Asp92Tyr), and seven metastases.

The mean patient age at diagnosis was 46 years (range 16-76 years) and 54 years (range 36-63 years) for the benign and malignant series respectively. The mean primary tumor diameter was $3.9 \mathrm{~cm}$ (range $0.9-6 \mathrm{~cm}$ ) for the benign series and $8.7 \mathrm{~cm}$ (range $0.7-15 \mathrm{~cm}$ ) for the malignant series. Patient characteristics and clinical data are summarized in Table 1.

\section{DNA preparation}

Forty-seven tumor DNA samples were isolated from four macroscopically separated areas within the paraffin-embedded tumors of 11 patients, and from three areas within the tumor of one patient with benign tumors. Matching normal DNA was isolated from paraffin-embedded healthy tissues of other unaffected organs or normal tissue surrounding the tumor. For the malignant tumors, an additional DNA sample was isolated from metastatic tissue (Fig. 1). In total, 37 tumor DNA samples were isolated from the PCC or sPGL, and metastases of the patients with malignant tumors. From patient 18, only one small primary tumor and two metastases were available for investigation, of which three tumor DNA samples were isolated. Furthermore, of patient 19, only the primary tumor was available and used to isolate four tumor DNA samples.

DNA was isolated using the D-5000 Puregene DNA Isolation kit (Gentra Systems, Minneapolis, MN, USA) according to the manufacturer's recommendations. Before and after DNA extraction, hematoxylin and eosin staining of each section was performed to confirm the percentage of tumor cells in the isolated samples, which was above $80 \%$ for proper $\mathrm{LOH}$ analysis.

Table 1 Clinical data of pheochromocytoma and extra-adrenal sympathetic paraganglioma patients

\begin{tabular}{|c|c|c|c|c|c|c|c|c|}
\hline & Patient & Gender & $\begin{array}{c}\text { Age } \\
\text { (years) }\end{array}$ & Other features & $\begin{array}{c}\text { Location } \\
\text { primary } \\
\text { tumor }\end{array}$ & $\begin{array}{l}\text { Tumor } \\
\text { diameter } \\
(\mathrm{cm})\end{array}$ & $\begin{array}{l}\text { Tumor } \\
\text { weight } \\
\text { (g) }\end{array}$ & $\begin{array}{l}\text { Location } \\
\text { metastases }\end{array}$ \\
\hline \multirow[t]{11}{*}{ Benign } & 1 & $\mathrm{~F}$ & 76 & - & a & 4 & 25 & - \\
\hline & 2 & $\mathrm{~F}$ & 39 & - & a & 6 & 54.3 & - \\
\hline & 3 & $\mathrm{~F}$ & 55 & - & ea & 6 & 24 & - \\
\hline & 4 & M & 16 & PCC-PGL syndrome & $\mathrm{a}$ & 4.5 & 68.1 & - \\
\hline & 5 & $\mathrm{~F}$ & 31 & PCC-PGL syndrome & a & $\mathrm{u}$ & 38 & - \\
\hline & 6 & M & 29 & NF1 & a & 3 & 18.8 & - \\
\hline & 7 & $M$ & 65 & - & a & 4.5 & 78 & - \\
\hline & 8 & $\mathrm{~F}$ & 46 & Renal cell carcinoma & a & 2 & 14 & - \\
\hline & 9 & $M$ & 52 & NF1 & a & $\mathrm{u}$ & $\mathrm{u}$ & - \\
\hline & 10 & $\mathrm{u}$ & u & - & a & 4 & 22 & - \\
\hline & 11 & $\mathrm{~F}$ & 51 & MEN2A - bilateral & a & $4 / 0.9$ & $23 / 19$ & - \\
\hline \multirow[t]{8}{*}{ Malignant } & 12 & $M$ & 62 & - & a & 5 & 176 & Abdomen \\
\hline & 13 & $\mathrm{~F}$ & 63 & - & a & 10 & u & Lymph nodes \\
\hline & 14 & $\mathrm{~F}$ & 61 & - & $\mathrm{a}$ & 12 & u & Lymph nodes \\
\hline & 15 & M & 42 & - & a & 8.5 & 166 & Abdomen \\
\hline & 16 & M & 61 & - & a & $\mathrm{u}$ & u & Lymph nodes \\
\hline & 17 & $\mathrm{~F}$ & 43 & - & $\mathrm{a}$ & 0.7 & 23 & Abdomen \\
\hline & 18 & M & 36 & - & $a$ & 15 & $\mathrm{u}$ & $\begin{array}{l}\text { Lymph nodes } \\
\text { and liver }\end{array}$ \\
\hline & 19 & M & 62 & PCC-PGL syndrome & ea & 10 & 264 & Liver \\
\hline
\end{tabular}

$\mathrm{F}=$ female, $\mathrm{M}=$ male, $\mathrm{a}=$ adrenal, ea=extra-adrenal, $\mathrm{u}=$ unknown. 


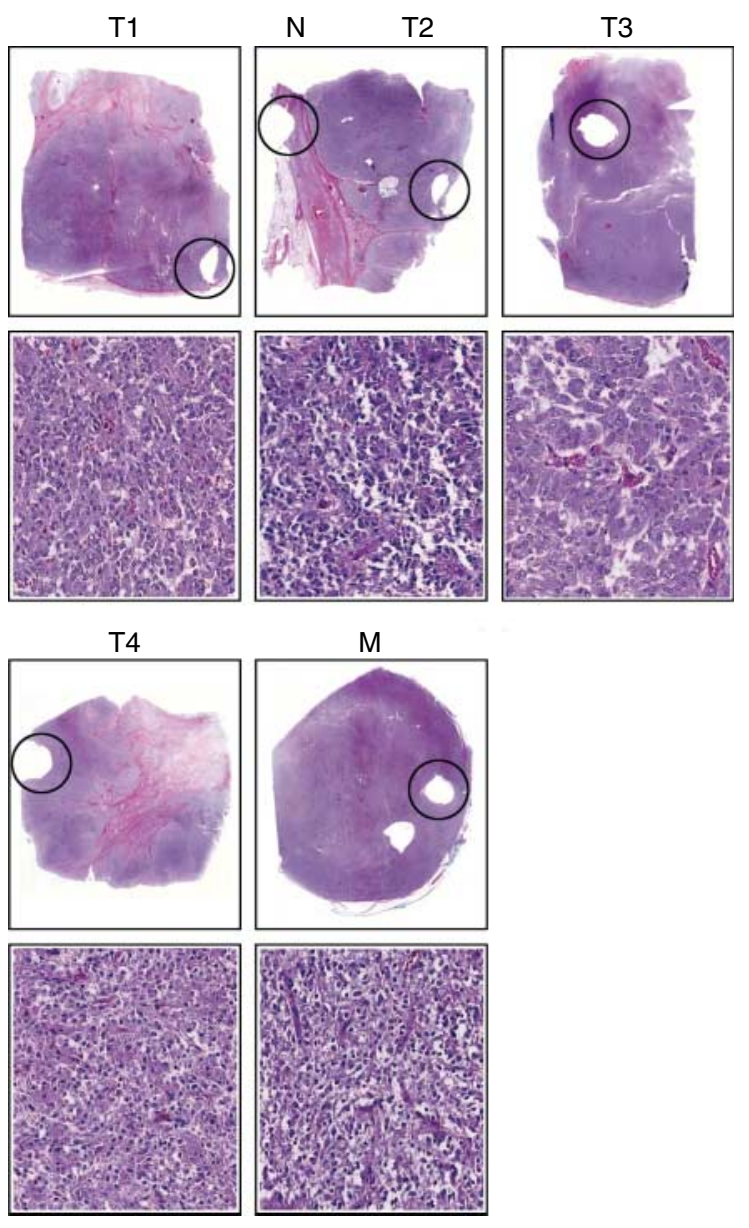

Figure 1 Upper panel shows the hematoxylin and eosin staining of slides of five different blocks from the PCC and metastasis of patient 13. From each block, one tumor DNA was isolated (T1-T4 and M). Normal DNA (N) was isolated from healthy tissue surrounding the PCC in block T2+N. The lower panel shows the $20 \times$ magnification of the slides of the upper panel.

\section{LOH analysis}

LOH analysis was performed with two different methods, using ten markers on five loci, which have been reported to be frequently lost in PCC. The markers selected were localized on chromosomes 1p13 (D1S252 and D1S2881), 1p36 (D1S2885 and D1S234), 3p13 (D3S3681 and D3S3551), 3q24 (D3S1569 and D3S3694), and 11p13 (D11S4083 and D11S4203).

The first PCR method was carried out using a32P-dATP (Amersham) and run on a denaturing 6\% polyacrylamide gel (Fluka, Neu-Ulm, Germany). In brief, PCR was performed with $1-\mu 1$ DNA $(30-100 \mathrm{ng} / \mu \mathrm{l})$ in a final volume of $15 \mu \mathrm{l}$ containing $1.5 \mathrm{mM} \mathrm{MgCl}_{2}, 10 \mathrm{mM}$ Tris- $\mathrm{HCl}, 50 \mathrm{mM} \mathrm{KCl}$, $0.02 \mathrm{mM}$ dATP, $0.2 \mathrm{mM}$ dGTP, dTTP, and dCTP, $0.8 \mu \mathrm{Ci} \alpha 32 \mathrm{P}-\mathrm{dATP}, 15 \mathrm{pmol}$ of each forward and reverse primer, and $1 \mathrm{U}$ Taq polymerase (Promega). PCR was performed for 35 cycles of $95^{\circ} \mathrm{C}$ for $30 \mathrm{~s}$, $58{ }^{\circ} \mathrm{C}$ for $45 \mathrm{~s}$, and $1 \mathrm{~min}$ at $72{ }^{\circ} \mathrm{C}$, followed by 1 cycle at $72{ }^{\circ} \mathrm{C}$ for $10 \mathrm{~min}$. PCR products of tumor and normal DNA were run on a denaturing $6 \%$ polyacrylamide gel (Fluka). After electrophoresis for $2 \mathrm{~h}$ at $65 \mathrm{~W}$, the gels were dried and exposed to X-ray films. The results were confirmed by a previously described PCR method (Gaal et al. 2009), using fluorescencelabeled primers (Invitrogen) and ABI 3130-XL genetic analyzer (Applied Biosystems, Foster City, CA, USA) for analysis. The results of both methods were analyzed by two independent investigators (W D and E K).

Cases were classified as informative when two alleles were found in normal DNA. When relative intensities of allelic signals observed in tumor DNA clearly differed from those in normal DNA, this was considered as loss. LOH was further categorized as loss of the lower (or smaller) or upper (or larger) allele. A tumor was considered genetically heterogeneous when $\mathrm{LOH}$ was present in at least one sample but not in all the samples of the same tumor or if the samples differed in loss of a lower or upper allele.

\section{Results}

\section{LOH frequencies}

Results of the $\mathrm{LOH}$ analysis for each marker in the benign and malignant tumors are shown in Figures 2 and 3 respectively. The data are also summarized for both tumor groups in Table 2. PCR with a second marker was only performed if the patient was not informative for the first marker for the investigated locus.

Most frequent losses were found for chromosome $1 \mathrm{p}$ occurring in up to $75 \%$ (considering $1 \mathrm{p} 13$ ) for both benign and malignant tumors. Loss of chromosome $3 q$ occurred in $45 \%(5 / 11)$ of the benign tumors, and in $63 \%(5 / 8)$ of the malignant tumors. Loss of chromosome $3 p$ was found in $25 \%$ (3/12) of the benign tumors and in $38 \%(3 / 8)$ of the malignant tumors. In addition, loss of chromosome $11 \mathrm{p}$ was seen in 50\% (6/12) of the benign tumors and in $17 \%(1 / 6)$ of the malignant tumors. One PCC (patient 16) of the malignant series did not reveal any LOH.

Notably, two malignant tumors showed homogeneous $\mathrm{LOH}$ patterns in the different primary tumor samples, but no LOH in the DNA derived from the metastasis. This occurred in patient 12 for chromosome 3 p12 and in patient 17 for chromosome 1 p13. The overall LOH frequency did not differ between the benign (44\%) and malignant (47\%) tumors. 


\begin{tabular}{|c|c|c|c|c|c|c|c|c|c|}
\hline \multirow[b]{2}{*}{ Locus } & \multirow[b]{2}{*}{ Patient } & \multicolumn{4}{|c|}{ Marker 1} & \multicolumn{4}{|c|}{ Marker 2} \\
\hline & & T1 & T2 & T3 & T4 & T1 & T2 & T3 & T4 \\
\hline \multirow[t]{12}{*}{$1 \mathrm{p} 13$} & 1 & & & & & $x$ & $x$ & $x$ & $x$ \\
\hline & 2 & & & & & $x$ & $x$ & $x$ & $x$ \\
\hline & 3 & & & & & $x$ & $\mathrm{x}$ & $x$ & $x$ \\
\hline & 4 & & & & & & & & \\
\hline & 5 & $\mathrm{NI}$ & $\mathrm{NI}$ & $\mathrm{NI}$ & $\mathrm{NI}$ & & & & \\
\hline & 6 & & & & & $\mathrm{NI}$ & $\mathrm{NI}$ & $\mathrm{NI}$ & $\mathrm{NI}$ \\
\hline & 7 & & & & & $x$ & $\mathrm{x}$ & $x$ & $x$ \\
\hline & 8 & & & & & $x$ & $x$ & $\mathrm{x}$ & $x$ \\
\hline & 9 & $\mathrm{NI}$ & $\mathrm{NI}$ & $\mathrm{NI}$ & - & & & & - \\
\hline & 10 & & & & & $x$ & $x$ & $x$ & $x$ \\
\hline & $11 \mathrm{~A}$ & & & & & $x$ & $x$ & $x$ & $x$ \\
\hline & $11 \mathrm{~B}$ & & & & & $x$ & $x$ & $x$ & $x$ \\
\hline \multirow[t]{12}{*}{$1 p 36$} & 1 & & & & & & & & \\
\hline & 2 & & & & & $\mathrm{NI}$ & $\mathrm{NI}$ & $\mathrm{NI}$ & $\mathrm{NI}$ \\
\hline & 3 & & & & & & & & \\
\hline & 4 & & & & & & & & \\
\hline & 5 & $\mathrm{NI}$ & $\mathrm{NI}$ & $\mathrm{NI}$ & $\mathrm{NI}$ & & 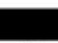 & 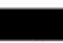 & 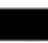 \\
\hline & 6 & & & & & $\mathrm{x}$ & $x$ & $\mathrm{x}$ & $x$ \\
\hline & 7 & & & & & $x$ & $x$ & $x$ & $x$ \\
\hline & 8 & & & & & $x$ & $x$ & $x$ & $x$ \\
\hline & 9 & & & & - & $x$ & $x$ & $x$ & $x$ \\
\hline & 10 & & & & & $x$ & $x$ & $x$ & $x$ \\
\hline & $11 \mathrm{~A}$ & $\mathrm{NI}$ & $\mathrm{NI}$ & $\mathrm{NI}$ & $\mathrm{NI}$ & & & & 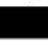 \\
\hline & $11 \mathrm{~B}$ & $\mathrm{NI}$ & $\mathrm{NI}$ & $\mathrm{NI}$ & $\mathrm{NI}$ & & & & \\
\hline \multirow[t]{12}{*}{$3 q 24$} & 1 & & & & & $x$ & $x$ & $x$ & $x$ \\
\hline & 2 & & & & & $x$ & $x$ & $x$ & $x$ \\
\hline & 3 & & & & & & & & \\
\hline & 4 & & & & & $x$ & $x$ & $x$ & $x$ \\
\hline & 5 & $\mathrm{NI}$ & $\mathrm{NI}$ & $\mathrm{NI}$ & $\mathrm{NI}$ & & & & \\
\hline & 6 & & & & & & & & \\
\hline & 7 & $\mathrm{NI}$ & $\mathrm{NI}$ & $\mathrm{NI}$ & $\mathrm{NI}$ & & & & \\
\hline & 8 & $\mathrm{NI}$ & $\mathrm{NI}$ & $\mathrm{NI}$ & $\mathrm{NI}$ & $\mathrm{NI}$ & $\mathrm{NI}$ & $\mathrm{NI}$ & $\mathrm{NI}$ \\
\hline & 9 & $\mathrm{NI}$ & $\mathrm{NI}$ & $\mathrm{NI}$ & - & & . & . & - \\
\hline & 10 & & & & $x$ & & & & \\
\hline & $11 \mathrm{~A}$ & & & & & $x$ & $x$ & $\mathrm{x}$ & $x$ \\
\hline & $11 \mathrm{~B}$ & & & & & $x$ & $x$ & $x$ & $x$ \\
\hline \multirow[t]{12}{*}{ 3p12 } & 1 & & & & & $x$ & $x$ & $x$ & $x$ \\
\hline & 2 & & & & & $x$ & $x$ & $x$ & $x$ \\
\hline & 3 & & & & & $x$ & $x$ & $x$ & $x$ \\
\hline & 4 & & & & & $x$ & $x$ & $x$ & $x$ \\
\hline & 5 & & & & & $x$ & $x$ & $x$ & $x$ \\
\hline & 6 & & & & & $x$ & $x$ & $x$ & $x$ \\
\hline & 7 & & & & & $x$ & $x$ & $x$ & $x$ \\
\hline & 8 & $\mathrm{NI}$ & $\mathrm{NI}$ & $\mathrm{NI}$ & $\mathrm{NI}$ & & & & \\
\hline & 9 & & & & - & & & & - \\
\hline & 10 & & & & & $x$ & $x$ & $x$ & $x$ \\
\hline & $11 \mathrm{~A}$ & & & & & $x$ & $x$ & $x$ & $x$ \\
\hline & $11 \mathrm{~B}$ & & & & & $x$ & $x$ & $x$ & $x$ \\
\hline \multirow[t]{12}{*}{$11 \mathrm{p} 13$} & 1 & $\mathrm{NI}$ & $\mathrm{NI}$ & $\mathrm{NI}$ & $\mathrm{NI}$ & & & & \\
\hline & 2 & & & & & & & & \\
\hline & 3 & & & & & $x$ & $x$ & $x$ & $x$ \\
\hline & 4 & & & & & $x$ & $x$ & $x$ & $x$ \\
\hline & 5 & & & & & & & & \\
\hline & 6 & & & & & $x$ & $x$ & $x$ & $x$ \\
\hline & 7 & $\mathrm{NI}$ & $\mathrm{NI}$ & $\mathrm{NI}$ & $\mathrm{NI}$ & & & & \\
\hline & 8 & & & & & $x$ & $x$ & $x$ & $x$ \\
\hline & 9 & & & & - & $x$ & $x$ & $x$ & $x$ \\
\hline & 10 & & & & & $x$ & $x$ & $x$ & $x$ \\
\hline & $11 \mathrm{~A}$ & & & & & $x$ & $x$ & $x$ & $x$ \\
\hline & $11 \mathrm{~B}$ & & & & & $x$ & $x$ & $x$ & $x$ \\
\hline
\end{tabular}

Figure 2 Loss of heterozygosity $(\mathrm{LOH})$ results of the benign pheochromocytomas and extra-adrenal sympathetic paragangliomas.

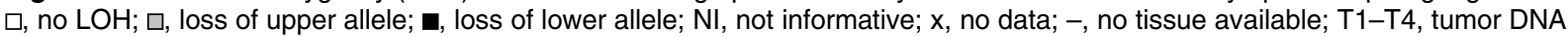
samples from different areas of the tumor. 


\begin{tabular}{|c|c|c|c|c|c|c|c|c|c|c|c|c|c|}
\hline \multirow[b]{2}{*}{ Locus } & \multirow[b]{2}{*}{ Patient } & \multicolumn{6}{|c|}{ Marker 1} & \multicolumn{6}{|c|}{ Marker 2} \\
\hline & & T1 & T2 & T3 & T4 & $M$ & M2 & T1 & T2 & T3 & T4 & M & M2 \\
\hline \multirow[t]{8}{*}{$1 \mathrm{p} 13$} & 12 & & & & & & - & $x$ & $x$ & $x$ & $x$ & $x$ & - \\
\hline & 13 & $\mathrm{NI}$ & $\mathrm{NI}$ & $\mathrm{NI}$ & $\mathrm{NI}$ & $\mathrm{NI}$ & - & & & & & & - \\
\hline & 14 & & & & & & - & $\mathrm{NI}$ & $\mathrm{NI}$ & $\mathrm{NI}$ & $\mathrm{NI}$ & $\mathrm{NI}$ & - \\
\hline & 15 & & & & & & - & $\mathrm{NI}$ & $\mathrm{NI}$ & $\mathrm{NI}$ & $\mathrm{NI}$ & $\mathrm{NI}$ & - \\
\hline & 16 & & & & & & - & $x$ & $x$ & $x$ & $x$ & $x$ & - \\
\hline & 17 & $\mathrm{NI}$ & $\mathrm{NI}$ & $\mathrm{NI}$ & $\mathrm{NI}$ & $\mathrm{NI}$ & - & & & & & & - \\
\hline & 18 & & - & - & - & 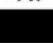 & 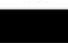 & $x$ & - & - & - & $x$ & $x$ \\
\hline & 19 & $\mathrm{NI}$ & $\mathrm{NI}$ & $\mathrm{NI}$ & $\mathrm{NI}$ & - & - & & & & & - & - \\
\hline \multirow[t]{9}{*}{$1 p 36$} & & T1 & T2 & T3 & T4 & $M$ & M2 & T1 & T2 & T3 & T4 & M & M2 \\
\hline & 12 & & & & & & - & $x$ & $x$ & $x$ & $x$ & $x$ & - \\
\hline & 13 & & & & & & - & $x$ & $x$ & $x$ & $x$ & $x$ & - \\
\hline & 14 & & & & & & - & & & & & & - \\
\hline & 15 & & & & & & - & & & & & 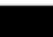 & - \\
\hline & 16 & & & & & & - & & & & & & - \\
\hline & 17 & & & & & & - & $\mathrm{NI}$ & $\mathrm{NI}$ & $\mathrm{NI}$ & $\mathrm{NI}$ & $\mathrm{NI}$ & - \\
\hline & 18 & & - & - & - & & . & $x$ & - & - & - & $x$ & $x$ \\
\hline & 19 & & & & & - & - & $x$ & $x$ & $x$ & $x$ & - & - \\
\hline \multirow[t]{9}{*}{$3 q 24$} & & $\mathrm{~T} 1$ & T2 & T3 & T4 & $M$ & M2 & T1 & T2 & T3 & T4 & M & M2 \\
\hline & 12 & & & & & & - & $x$ & $x$ & $x$ & $x$ & $x$ & - \\
\hline & 13 & $\mathrm{NI}$ & $\mathrm{NI}$ & $\mathrm{NI}$ & $\mathrm{NI}$ & $\mathrm{NI}$ & - & & & & & & - \\
\hline & 14 & & & & & & - & $x$ & $x$ & $x$ & $x$ & $x$ & - \\
\hline & 15 & & & & & & - & $x$ & $x$ & $x$ & $x$ & $x$ & - \\
\hline & 16 & & & & & & - & $x$ & $x$ & $x$ & $x$ & $x$ & - \\
\hline & 17 & & & & & & - & $\mathrm{NI}$ & $\mathrm{NI}$ & $\mathrm{NI}$ & $\mathrm{NI}$ & $\mathrm{NI}$ & - \\
\hline & 18 & & - & - & - & & & $x$ & - & - & - & $x$ & $x$ \\
\hline & 19 & $\mathrm{NI}$ & $\mathrm{NI}$ & $\mathrm{NI}$ & $\mathrm{NI}$ & - & - & & & & & - & - \\
\hline \multirow[t]{9}{*}{ 3p12 } & & T1 & T2 & T3 & T4 & $M$ & M2 & $\mathrm{T} 1$ & T2 & T3 & T4 & M & M2 \\
\hline & 12 & & & & & & - & $x$ & $x$ & $x$ & $x$ & $x$ & - \\
\hline & 13 & $\mathrm{NI}$ & $\mathrm{NI}$ & $\mathrm{NI}$ & $\mathrm{NI}$ & $\mathrm{NI}$ & - & 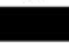 & 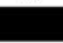 & & 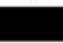 & 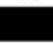 & - \\
\hline & 14 & $\mathrm{NI}$ & $\mathrm{NI}$ & $\mathrm{NI}$ & $\mathrm{NI}$ & $\mathrm{NI}$ & - & & & & & & - \\
\hline & 15 & & & & & & - & $x$ & $x$ & $x$ & $x$ & $x$ & - \\
\hline & 16 & & & & & & - & $x$ & $x$ & $x$ & $x$ & $x$ & - \\
\hline & 17 & & & & & & - & $x$ & $x$ & $x$ & $x$ & $x$ & - \\
\hline & 18 & $\mathrm{NI}$ & - & - & - & $\mathrm{NI}$ & $\mathrm{NI}$ & & - & - & - & & \\
\hline & 19 & $\mathrm{NI}$ & $\mathrm{NI}$ & $\mathrm{NI}$ & $\mathrm{NI}$ & - & - & & & & & - & - \\
\hline \multirow[t]{9}{*}{$11 \mathrm{p} 13$} & & $\mathrm{~T} 1$ & T2 & T3 & T4 & $M$ & M2 & $\mathrm{T} 1$ & T2 & T3 & T4 & $M$ & M2 \\
\hline & 12 & & & & & & - & $x$ & $x$ & $x$ & $x$ & $x$ & - \\
\hline & 13 & & & & & & - & $x$ & $x$ & $x$ & $x$ & $x$ & - \\
\hline & 14 & & & & & & - & $x$ & $x$ & $x$ & $x$ & $x$ & - \\
\hline & 15 & $\mathrm{NI}$ & $\mathrm{NI}$ & $\mathrm{NI}$ & $\mathrm{NI}$ & $\mathrm{NI}$ & - & $x$ & $x$ & $x$ & $x$ & $x$ & - \\
\hline & 16 & & & & & & - & $x$ & $x$ & $x$ & $x$ & $x$ & - \\
\hline & 17 & & & & & & - & $x$ & $x$ & $x$ & $x$ & $x$ & - \\
\hline & 18 & & - & - & - & & & $x$ & $x$ & $x$ & $x$ & $x$ & $x$ \\
\hline & 19 & $\mathrm{NI}$ & $\mathrm{NI}$ & $\mathrm{NI}$ & $\mathrm{NI}$ & - & - & $x$ & $x$ & $x$ & $x$ & $x$ & - \\
\hline
\end{tabular}

Figure $3 \mathrm{LOH}$ results of the malignant pheochromocytomas and extra-adrenal sympathetic paragangliomas. $\square=\mathrm{no} L \mathrm{LH}, \square=$ loss of upper allele, $\boldsymbol{\nabla}=$ loss of lower allele, $\mathrm{NI}=$ not informative, $\mathrm{x}=$ no data, $-=$ no tissue available, $\mathrm{T} 1-\mathrm{T} 4=$ tumor DNA samples from different areas of the tumor, $\mathrm{M}$ and $\mathrm{M} 2=$ tumor DNA samples of two different PCC metastases.

\section{Heterogeneity frequencies}

A summary of the intra-tumoral heterogeneity results is shown in Table 2. An example of heterogeneity is illustrated in Fig. 4. Tumor DNAs were isolated from macroscopically different parts of the tumor. There was no correlation between histology and molecular heterogeneity, as these macroscopically different parts were histologically similar (Fig. 1). Intra-tumoral heterogeneity was found in $42 \%(5 / 12)$ and $75 \%(6 / 8)$ of the benign and malignant tumors respectively. In the 
Table 2 Overview of loss of heterozygosity $(\mathrm{LOH})$ and intra-tumoral heterogeneity results

\begin{tabular}{|c|c|c|c|c|c|}
\hline & $1 p 13$ & $1 \mathrm{p} 36$ & $3 q$ & $3 p$ & $11 p$ \\
\hline \multicolumn{6}{|l|}{ Benign tumors } \\
\hline $\mathrm{LOH}$ & $9 / 12(75)$ & $8 / 12(67)$ & $5 / 11(45)$ & $3 / 12(25)$ & $6 / 12(50)$ \\
\hline Intra-tumoral heterogeneity & $1 / 12(8)$ & $2 / 12(17)$ & $1 / 11(9)$ & $0 / 12(0)$ & $2 / 12(17)$ \\
\hline \multicolumn{6}{|l|}{ Malignant tumors } \\
\hline $\mathrm{LOH}$ & $6 / 8(75)$ & $5 / 8(63)$ & $5 / 8(63)$ & $3 / 8(38)$ & $1 / 6(17)$ \\
\hline Intra-tumoral heterogeneity & $3 / 8(38)$ & $2 / 8(25)$ & $3 / 8(38)$ & $1 / 8(13)$ & $0 / 6(0)$ \\
\hline
\end{tabular}

Numbers (in brackets percentages) represent LOH or heterogeneity observed in patients/total patients that were informative.

chromosomal regions reported to have high frequencies of $\mathrm{LOH}$ in PCC (chromosome $1 \mathrm{p} 13$ and chromosome $3 q$ ), there was more intra-tumoral heterogeneity present in the malignant tumors $(37.5 \%$ for both regions) compared with the benign tumors ( $8.3 \%$ for both regions). In contrast, chromosome $11 \mathrm{p}$ showed no intra-tumoral heterogeneity in the malignant tumors, compared with $16.7 \%$ in the benign tumors. Additionally, the average frequency of intratumoral heterogeneity of the malignant tumors $(22.5 \%)$ was higher than of the benign tumors $(10.2 \%)$.

\section{Syndrome-related PCC LOH results}

Remarkably, both PCCs of the MEN 2A patient (patient 11) revealed different aberrations in chromosomal region 1p13: in both tumors, opposing 1p13 allele loss was observed homogeneously in all tumor samples of each tumor (Fig. 2). In addition, tumor A of patient 11 showed homogeneous loss of chromosome $3 q 24$ in all tumor samples, whereas the contralateral tumor B did not display $3 \mathrm{q} 24 \mathrm{LOH}$ in any of the tumor DNA samples (Fig. 2).

Three patients had PCC-PGL syndrome caused by a germline $S D H D$ mutation (localized on chromosome 11). The PCC of two PCC-PGL syndrome patients (Fig. 2, cases 4 and 5) showed LOH of chromosome $11 \mathrm{p}$ in all tumor samples; the sPGL of the other patient (Fig. 3, case 19) was not informative for the chromosome 11 marker. In addition, two patients had NF1-related PCC (characterized by loss of chromosome 1p36), which both displayed homogeneous loss of 1p36 in all samples (Fig. 2, cases 6 and 9).

\section{Discussion}

The knowledge of intra-tumoral molecular heterogeneity in PCC and SPGL is important for understanding the pathogenesis of these tumors. In addition, heterogeneity can have consequences for interpretation of molecular data. Therefore, we determined the intratumoral molecular heterogeneity in a series of 12 benign tumors (11 PCC and 1 sPGL) and 8 malignant tumors (seven PCC and one sPGL) by LOH analysis in different areas of the tumors. Molecular intra-tumoral heterogeneity within tumors has been reported in $55 \%$ of meningiomas (Sayagues et al. 2004), 45\% of renal tumors (Nenning et al. 1997), 2.7\% of cervical cancer (Bachtiary et al. 2006), and in $8.8 \%$ of PCC (Diaz-Cano et al. 2000). It is important to emphasize that these frequencies show extreme variation because 1) the amount of markers or probes used per study are different. The more probes being used, the more heterogeneity is found. In case of Bachtiary et al. (2006) who used expression arrays to investigate a series of cervical cancer, a ratio of two internal controls was used to determine intra-tumoral heterogeneity. A ratio of more than 0.90 was considered as high heterogeneity $(2.7 \%)$, whereas $<0.10$ was regarded as extreme low heterogeneity $(2.2 \%)$. In contrast, ratios in between had a global lower heterogeneity, so the frequency of heterogeneity will be up to $100 \%$; 2) other studies used only few markers or probes (Nenning et al. 1997, Diaz-Cano et al. 2000, Sayagues et al. 2004), whose genomic location is of great importance. When probes are chosen in genomic areas that are lost early in pathogenesis, the tumors will show no or little intra-tumoral heterogeneity, whereas probes on chromosomes that are altered later in tumorigenesis will result in high frequencies of heterogeneity; and 3) PCC can occur in several syndromes, such as the MEN 2 syndrome, VHL disease, or the PCC-PGL syndrome. The PCCs in these syndromes have different alterations that occur early in the pathogenesis, such as loss of chromosomes $1 \mathrm{p}$ and $3 \mathrm{q}$ in MEN 2-related PCC and loss of chromosome 11 in SDHD-related PCC. This could explain why SDHD-related PCCs show heterogeneity for markers on chromosome 1p, and MEN 2-related PCCs show heterogeneity for markers on chromosome $11 \mathrm{q}$ in our study. LOH of these chromosomes was most likely a late event in the pathogenesis in both PCCs.

Our LOH results, showing heterogeneity in only 1 of the 12 benign tumors, are in concurrence with literature reports since chromosomes 1 p13 and $3 q$ are reported as early aberrations in benign sporadic and MEN 2A-related PCC (Dannenberg et al. 2000, van Nederveen et al. 2009) and loss of chromosome 1 p36 is the most 


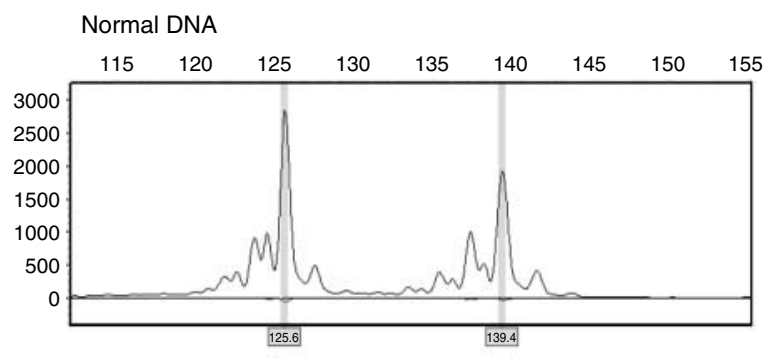

Tumor DNA 1

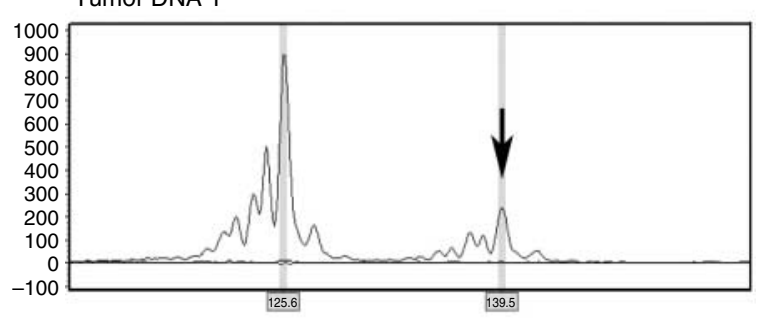

Tumor DNA 2

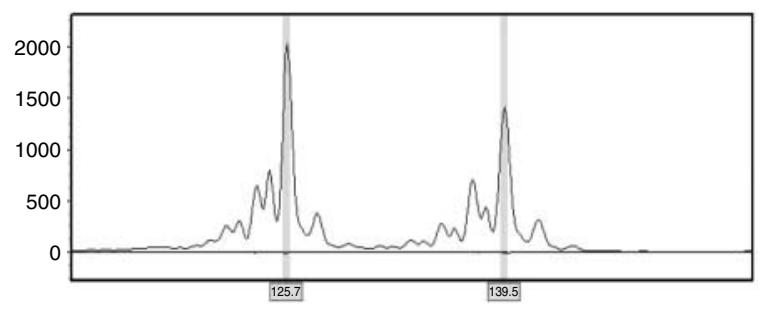

Tumor DNA 3

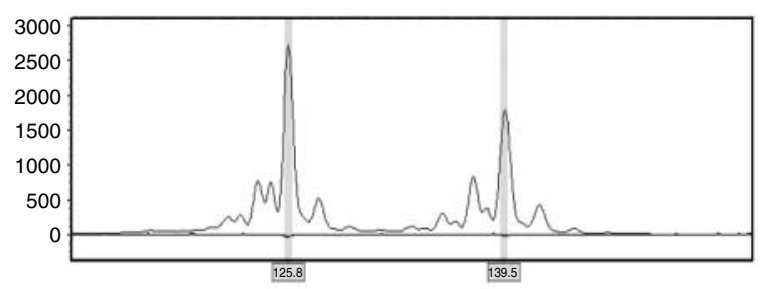

Tumor DNA 4

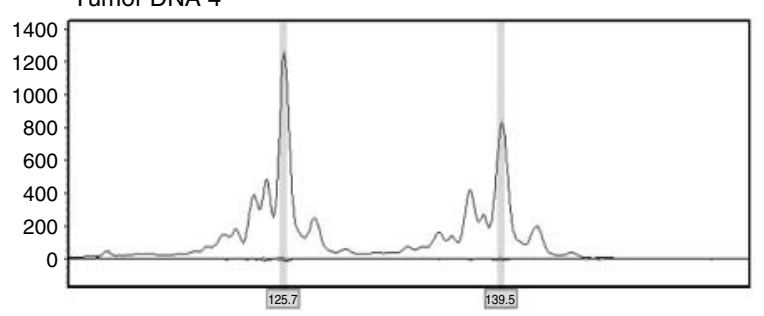

Figure 4 Loss of heterozygosity (LOH) result for marker D1S252 of patient 4. N represents normal DNA and T1-T4 indicates the different tumor DNAs. The deleted allele in $\mathrm{T} 1$ is indicated by an arrow. The other tumor DNAs (T1, T3, and T4) do not show LOH.

frequent molecular alteration in NF1-related PCC (Edstrom et al. 2000, Bausch et al. 2007). The tumor showing heterogeneous loss of chromosomes $1 \mathrm{p} 13$ and 3q24 was an SDHD-related PCC, with consistent identical $\mathrm{LOH}$ of $11 \mathrm{p}$ in all tumor samples, indicating monoclonal origin. SDHD-related tumors are characterized by bi-allelic inactivation of the $S D H D$ gene: the combination of a germline mutation in the SDHD gene and loss of the remaining wild-type allele (11q23). Therefore, in SDHD-related tumors, loss of the wild-type chromosome $11 \mathrm{q}$ allele is most likely the tumor-initiating event preceding loss of chromosome $1 \mathrm{p}$.

MEN 2A-related PCCs are characterized by loss of chromosomes 1p and 3q (Edstrom et al. 2000, Jarbo et al. 2005, van Nederveen et al. 2009). Our study included one MEN 2A patient with bilateral benign PCC. In both tumors, homogeneous loss of chromosome $1 \mathrm{p}$ in all tumor samples was found. However, both tumors showed loss of opposing $1 \mathrm{p}$ alleles. In addition, loss of chromosome $3 \mathrm{q}$ was seen in only one of the bilateral PCC. The PCC of this MEN 2A patient showed inter-tumoral heterogeneity, indicating that these tumors occurred independently.

It is generally accepted that neoplastic cells harbor clonal molecular aberrations and normal cells do not. Tumors, like PCC and sPGL, are composed of neoplastic and normal cells. Consequently, DNA isolated from a - part of - PCC or sPGL is composed of DNA of neoplastic cells and normal cells. With LOH analyses, tumor and corresponding normal DNA are compared, so information about loss of DNA within the tumor sample can be obtained, but also information about which allele - or microsatellite marker - is lost. In this study, most tumor DNAs were isolated from parts that consisted of high percentages neoplastic cells, since histology of the tumor blocks was checked before and after DNA isolation. In addition, admixture of high percentage of normal cells would mask the detection of aberrations. In our study, all 48 DNA samples of the benign tumor series and in 29 of 37 DNA samples from the malignant series unequivocal $\mathrm{LOH}$ were observed with at least one LOH marker. This indicates that these DNA samples were all derived from a homogeneous tumor cell population with little admixture of normal - endothelial or stromal - cells. However, five DNA samples from patient 16 and in three of four samples from patient 19 did not show $\mathrm{LOH}$ with four and six informative markers respectively. This is probably due to the absence of genomic alterations at these loci, but to confirm this more markers should be tested.

Molecular heterogeneity could also be due to technical artifacts. However, although PCR-based assays can vary in sensitivity between loci, sensitivity is unlikely to differ between samples if the same primers and PCR conditions were used. The sensitivity of detecting $\mathrm{LOH}$ is based on the PCR sensitivity (is a PCR product generated or not), the size difference 
between the homologous alleles in the individual sample (small differences of e.g. one repeat unit, two nucleotides, are more difficult to evaluate than large differences) and the percentage of clonal neoplastic cells in the tumor fragment from which the DNA is isolated. But, because the $\mathrm{LOH}$ is determined per marker by comparing the tumor DNA with the normal DNA (of the same patient) retrieved from the same formalin-fixed paraffin-embedded (FFPE) tissue block, PCR efficiency is not influencing the results, as $\mathrm{LOH}$ is determined within one locus.

Previously, tumors were thought to become malignant through a multistep process, on the cellular level, of accumulation of mutations in benign tumor cells leading to malignant cellular transformation and intratumoral heterogeneity (Klein 2009). Recently, however, it has been hypothesized that tumors can already be malignant from the onset of tumorigenesis, and therefore would be less heterogeneous than thought previously (Klein 2009). Genomic aberrations of metastases in association with the primary tumor have been investigated (Edstrom et al. 2000, Jarbo et al. 2005, van Nederveen et al. 2009). Loss of chromosome $1 \mathrm{p}$ is an early event in the pathogenesis of malignant (sporadic) PCC (Dannenberg et al. 2000, Cascon et al. 2005). Our results show LOH of chromosome $1 \mathrm{p} 13$ in $75 \%$ of malignant tumors, half of those revealing heterogeneity. These results imply that loss of $1 \mathrm{p} 13$ is probably not an early event in the pathogenesis of these PCCs. Two of these three PCCs, heterogeneous for the loss of the $1 \mathrm{p} 13$ locus, showed homogeneous $\mathrm{LOH}$ for chromosome $1 \mathrm{p} 36$ or $3 \mathrm{p} 12$ and $3 q 24$, which suggests that these tumors are monoclonal proliferations with different genetic backgrounds.

It has been proposed that malignant tumors are generally larger than benign tumors, as was the case in our study. This suggests more cell divisions resulting in a higher chance of genetic aberrations. However, Dannenberg et al. (2000) showed that there was no correlation between tumor size and the number of alterations in a CGH study of benign and malignant PCC. Yet, Dannenberg et al. used a conventional method with a low resolution, so conclusions could only be made firmly about large genomic regions ( $>10 \mathrm{MB}$ ). Furthermore, another more recent study showed more genetic aberrations in malignant tumors compared with benign tumors (Shen et al. 2004). Therefore, malignant PCC could also demonstrate molecular heterogeneity at a higher frequency. However, it is very likely that molecular aberrations that occur early in the tumorigenic process will show no heterogeneity in different parts of the tumor. So, the increased frequency of molecular heterogeneity in malignant tumors in our study suggests a different molecular pathogenesis, rather than a bystander effect of the tumor size.

In conclusion, we have investigated intra-tumoral molecular heterogeneity in benign and malignant PCC, and found more heterogeneity in malignant tumors in general. Six of the eight malignant tumors showed intra-tumor heterogeneity for any of the markers studied. The markers on chromosome $1 \mathrm{p} 13$ and $3 \mathrm{q} 24$, which are lost early in the pathogenesis of benign PCC, result in more heterogeneous patterns in malignant tumors. This indicates that the malignant tumors might have a different molecular tumorigenesis in comparison with benign tumors, probably with losses and/or gains of other genomic regions as early events during pathogenesis. However, 4 of the 12 benign cases also showed intra-tumoral heterogeneity. Therefore, the results of our study also emphasize that caution must be taken when only small areas of a tumor are used for molecular studies. Only molecular aberrations that occurred early in tumorigenesis and have resulted in a pronounced selective growth advantage will be homogeneously present in the tumors. In addition, we demonstrated that intra-tumoral molecular heterogeneity occurred more often in malignant tumors than in benign tumors, suggesting that malignant and benign PCCs evolve along different tumorigenic processes. These findings suggest that benign and malignant PCCs can be different entities, whereby malignant tumors can be malignant from the onset and do not necessarily evolve from benign tumors.

\section{Declaration of interest}

The authors declare that there is no conflict of interest that could be perceived as prejudicing the impartiality of the research reported.

\section{Funding}

This research did not receive any specific grant from any funding agency in the public, commercial or not-forprofit sector.

\section{References}

Amar L, Baudin E, Burnichon N, Peyrard S, Silvera S, Bertherat J, Bertagna X, Schlumberger M, Jeunemaitre X, Gimenez-Roqueplo AP et al. 2007 Succinate dehydrogenase $\mathrm{B}$ gene mutations predict survival in patients with malignant pheochromocytomas or paragangliomas. Journal of Clinical Endocrinology and Metabolism 92 3822-3828.

Bachtiary B, Boutros PC, Pintilie M, Shi W, Bastianutto C, Li JH, Schwock J, Zhang W, Penn LZ, Jurisica I et al. 
2006 Gene expression profiling in cervical cancer: an exploration of intratumor heterogeneity. Clinical Cancer Research $125632-5640$.

Bausch B, Borozdin W, Mautner VF, Hoffmann MM, Boehm D, Robledo M, Cascon A, Harenberg T, Schiavi F, Pawlu C et al. 2007 Germline NF1 mutational spectra and loss-of-heterozygosity analyses in patients with pheochromocytoma and neurofibromatosis type 1. Journal of Clinical Endocrinology and Metabolism 92 2784-2792.

Benn DE, Richardson AL, Marsh DJ \& Robinson BG 2006 Genetic testing in pheochromocytoma- and paraganglioma-associated syndromes. Annals of the New York Academy of Sciences 1073 104-111.

Blackhall FH, Pintilie M, Wigle DA, Jurisica I, Liu N, Radulovich N, Johnston MR, Keshavjee S \& Tsao MS 2004 Stability and heterogeneity of expression profiles in lung cancer specimens harvested following surgical resection. Neoplasia 6 761-767.

Califano J, van der Riet P, Westra W, Nawroz H, Clayman G, Piantadosi S, Corio R, Lee D, Greenberg B, Koch W et al. 1996 Genetic progression model for head and neck cancer: implications for field cancerization. Cancer Research 56 2488-2492.

Cascon A, Ruiz-Llorente S, Rodriguez-Perales S, Honrado E, Martinez-Ramirez A, Leton R, Montero-Conde C, Benitez J, Dopazo J, Cigudosa JC et al. 2005 A novel candidate region linked to development of both pheochromocytoma and head/neck paraganglioma. Genes, Chromosomes and Cancer 42 260-268.

Cascon A, Pita G, Burnichon N, Landa I, Lopez-Jimenez E, Montero-Conde C, Leskela S, Leandro-Garcia LJ, Leton R, Rodriguez-Antona C et al. 2009 Genetics of pheochromocytoma and paraganglioma in Spanish patients. Journal of Clinical Endocrinology and Metabolism 94 1701-1705.

Dannenberg H, Speel EJ, Zhao J, Saremaslani P, van Der Harst E, Roth J, Heitz PU, Bonjer HJ, Dinjens WN, Mooi WJ et al. 2000 Losses of chromosomes $1 p$ and $3 q$ are early genetic events in the development of sporadic pheochromocytomas. American Journal of Pathology 157 353-359.

Diaz-Cano SJ, de Miguel M, Blanes A, Tashjian R, Galera H \& Wolfe HJ 2000 Clonal patterns in phaeochromocytomas and MEN-2A adrenal medullary hyperplasias: histological and kinetic correlates. Journal of Pathology 192 221-228.

Edstrom E, Mahlamaki E, Nord B, Kjellman M, Karhu R, Hoog A, Goncharov N, Teh BT, Backdahl M \& Larsson C 2000 Comparative genomic hybridization reveals frequent losses of chromosomes $1 p$ and $3 q$ in pheochromocytomas and abdominal paragangliomas, suggesting a common genetic etiology. American Journal of Pathology 156 651-659.

Gaal J, van Nederveen FH, Erlic Z, Korpershoek E, Oldenburg R, Boedeker CC, Kontny U, Neumann HP, Dinjens WN \& de Krijger RR 2009 Parasympathetic paragangliomas are part of the Von Hippel-Lindau syndrome. Journal of Clinical Endocrinology and Metabolism 94 4367-4371.
Gimenez-Roqueplo AP, Favier J, Rustin P, Rieubland C, Crespin M, Nau V, Khau Van Kien P, Corvol P, Plouin PF \& Jeunemaitre X 2003 Mutations in the SDHB gene are associated with extra-adrenal and/or malignant phaeochromocytomas. Cancer Research 63 5615-5621.

Hensen EF, Jordanova ES, van Minderhout IJ, Hogendoorn PC, Taschner PE, van der Mey AG, Devilee P \& Cornelisse CJ 2004 Somatic loss of maternal chromosome 11 causes parent-of-origin-dependent inheritance in SDHD-linked paraganglioma and phaeochromocytoma families. Oncogene 23 4076-4083.

Jarbo C, Buckley PG, Piotrowski A, Mantripragada KK, Benetkiewicz M, de Stahl TD, Langford CF, Gregory SG, Dralle H, Gimm O et al. 2005 Detailed assessment of chromosome 22 aberrations in sporadic pheochromocytoma using array-CGH. International Journal of Cancer 118 1159-1164.

Klein CA 2009 Parallel progression of primary tumours and metastases. Nature Reviews. Cancer 9 302-312.

Korpershoek E, Van Nederveen FH, Dannenberg H, Petri BJ, Komminoth P, Perren A, Lenders JW, Verhofstad AA, De Herder WW, De Krijger RR et al. 2006 Genetic analyses of apparently sporadic pheochromocytomas: the Rotterdam experience. Annals of the New York Academy of Sciences 1073 138-148.

Lenders JW, Eisenhofer G, Mannelli M \& Pacak K 2005 Phaeochromocytoma. Lancet 366 665-675.

Lui WO, Chen J, Glasker S, Bender BU, Madura C, Khoo SK, Kort E, Larsson C, Neumann HP \& Teh BT 2002 Selective loss of chromosome 11 in pheochromocytomas associated with the VHL syndrome. Oncogene 21 1117-1122.

van Nederveen F, Korpershoek E, Deleeuw R, Verhofstad AA, Lenders JW, Dinjens W, Lam W \& de Krijger R 2009 Array-CGH in sporadic benign pheochromocytomas. Endocrine-Related Cancer 16 505-513.

Nenning H, Rassler J \& Minh DH 1997 Heterogeneity of DNA distribution pattern in renal tumours. Analytical Cellular Pathology 14 9-17.

Neumann HP, Bausch B, McWhinney SR, Bender BU, Gimm O, Franke G, Schipper J, Klisch J, Altehoefer C, Zerres K et al. 2002 Germ-line mutations in nonsyndromic pheochromocytoma. New England Journal of Medicine 346 1459-1466.

Pacak K, Eisenhofer G, Ahlman H, Bornstein SR, GimenezRoqueplo AP, Grossman AB, Kimura N, Mannelli M, McNicol AM, Tischler AS et al. 2007 Pheochromocytoma: recommendations for clinical practice from the First International Symposium. October 2005. Nature Clinical Practice. Endocrinology \& Metabolism 3 92-102.

Sayagues JM, Tabernero MD, Maillo A, Espinosa A, Rasillo A, Diaz P, Ciudad J, Lopez A, Merino M, Goncalves JM et al. 2004 Intratumoral patterns of clonal evolution in meningiomas as defined by multicolor interphase fluorescence in situ hybridization (FISH): is there a relationship between histopathologically benign and atypical/anaplastic lesions? Journal of Molecular Diagnostics 6 316-325. 